\title{
Hubble stakes are high for NASA's future
}

Washington. At around 0500 Eastern Standard Time next Wednesday, 1 December last-minute delays notwithstanding — the US National Aeronautics and Space Administration (NASA) will launch a mission with a public profile unmatched since the Apollo programme of the $1960 \mathrm{~s}$. Its success or failure could have almost as much bearing on the troubled space agency's long-term prospects.

The countdown has already begun on the seven-astronaut shuttle mission to repair the Hubble space telescope, and NASA is putting a brave face on its impending trial. "We are not afraid", the agency's chief, Dan Goldin, told a Senate hearing last week. "If we fail, we will dust ourselves down and do it again."

But the stakes are uncomfortably high for the agency, particularly because the mission's five-day schedule of complex repairs by astronauts working outside the spacecraft makes it one of the most complex ever attempted.

"This is an exceedingly difficult mission, and NASA is under a cloud right now, so it is going to be closely watched by a lot of people," says Frank Gilbert of the National Space Society in Washington. If the mission fails, he says, the scientific and aerospace communities may be understanding; but he warns that the media - and NASA's enemies in Congress — will be

\section{Practising optical surgery in space}

Paris. Astronomers will be holding their breath on 3 December when a robot arm snatches the bus-sized Hubble Space Telescope (HST) into the cargo bay of the shuttle Endeavour. Astronauts will then set about correcting Hubble's blurred vision, replacing scientific instruments and servicing the telescope's on-board systems to keep it running until the shuttle's next visit in 1997.

Six-hundred kilometres above the Earth, Hubble has a clear view of the Universe in both the visible and ultraviolet range. Its 2.4-metre primary mirror is not big by modern standards. But this vantage point means that Hubble should outperform the largest land-based telescopes, giving it ten times better resolution (the ability to distinguish the two rear lights of a car at $10,000 \mathrm{~km}$ ) and thirty times greater sensitivity (able to detect a star that is a billion times fainter than the faintest visible to the naked eye).

But the first images from the telescope's Wide Field/Planetary Camera (WF/PC) and Faint Object Camera (FOC), three years ago, exposed spherical aberration in the telescope's primary mirror caused by a manufacturing error. The consequent loss of sensitivity also affected HST's three other scientific instruments - the Faint Object Spectrograph (FOS), the Goddard High Resolution Spectrograph (GHRS) and the High Speed Photometer.

Moreover, although all Hubble's major systems worked at first, three of its six gyroscopes (which help to point the telescope) and a computer memory board have since packed up. Power has also failed in part of the GHRS.

The solar arrays have also caused unexpected vibrations, which occur when the panels heat or cool suddenly between day and night orbits (once every $90 \mathrm{~min}$ utes). Changes to the HST pointing and control software have partly solved the problem, but the unpredictable onset of vibrations often leads to loss of fine lock during observations.

Some of Hubble's problems were unexpected. But the original mission plan anticipated regular shuttle missions to service parts of the telescope. To this end, all the scientific instruments and critical spacecraft systems have been designed as modules that can be replaced by astronauts.

This first service mission - which is also intended to test the feasibility of inorbit servicing (see above) - is planned to last 11 days. Five six-hour spacewalks are planned, and contingency plans allow for a further three.

"Minimum success" would involve fitting three new gyroscopes, and either the replacement of the Wide Field/Planetary Camera or fitting the COSTAR optics (Corrective Optics Space Telescope Axial Replacement)."Maximum success" would involve fitting the WF/PC, COSTAR, six new gyroscopes, the replacement solar arrays (thermally shielded, and redesigned to buffer thermal expansion and contraction) and one magnometer.

The COSTAR re-imaging mirrors will compensate the FOC, FOS and GHRS for the aberration in the primary mirror (the space occupied by COSTAR will require sacrificing the High Speed Photometer). The replacement WF/PC is equipped with its own system to correct the spherical aberration.

The first aberration-corrected pictures will not be available until around two months after Endeavour touches down at the Kennedy Space Center in Florida on 12 December. If all goes well, astronomers' attention will then turn to using the Hubble Space Telescope's long-awaited potential. ready to pounce.

The Hubble repair mission takes place as NASA is fighting a losing battle to fend off further budget cuts. Last week Goldin, who since his appointment last year has taken on the mantle of an outsider determined to cut down the agency's bureaucracy, pleaded with senators to desist from further cuts.

"We have cut and cut and cut the NASA programme", he told the Senate science, technology and space subcommittee. "Now we have reached the point where the prospect of additional cuts is of grave concern."

Goldin said that NASA's planned fiveyear budget had fallen from $\$ 96$ billion to $\$ 78$ billion in 18 months, and could now fall to $\$ 71$ billion. The budget was being changed "every two or three months", he said, calling on Congress to give him a stable amount of money to plan with.

Ken Ledbetter, programme manager for Hubble at the Goddard Space Flight Center in Greenbelt, Maryland, declines to comment on whether he is under special pressure from his bosses because of the importance the mission has assumed.

Ledbetter says that the agency has planned for as many contingencies as it can think of.

\section{IMAGE UNAVAILABLE FOR COPYRIGHT REASONS}

Good vibrations: new solar arrays should reduce problems encountered previously.

"We've constructed the repair tasks to be modular, we've cross-trained the crew, we have done so many things," he says. "But space is the frontier, and when you push the edge of the frontier, you sometimes hit the unexpected."

Indeed, it is the tendency of spacewalks to encounter unexpected problems that makes many observers sceptical about whether NASA can successfully complete the necessary 30 hours of repair work in the allotted time. NASA officials reply that the 11-day mission could be extended by as many as three days, and that a sixth day of 